\title{
HOURS OF WORK, LABOR PRODUCTIVITY, AND ENVIRONMENTAL CONDITIONS: A CASE STUDY
}

\author{
Thomas D. Crocker and Robert L. Horst, Jr.*
}

\section{Introduction}

$\mathrm{L}$ IVELIHOOD measures of foregone and compensating earnings are frequently used as measures of economic losses due to realized or potential damages to the health of labor inputs. Both measures as they have been used are incomplete, though for quite different reasons. The narrowness of the foregone earnings measure is widely acknowledged. ${ }^{1}$ As set forth in Smith (1974), Thaler and Rosen (1976), and Viscusi (1979), the compensating earnings measure, with its emphasis upon the earnings premia workers require to be willing to be exposed to job hazards they perceive, certainly has broader analytical appeal. However, as empirically implemented, these studies too are incomplete: they deal with worker and time aggregates allowing only crude measures of differences in reward structures, mixes of complementary inputs, work-day lengths, risk aversions, worker effort, and other dissimilar factors across individuals, firms, and industries.

In this paper, the productivity changes and consequent earnings adjustments that occur under differing work conditions for 17 individual citrus pickers in southern California are assessed. Interest is centered upon the acute effects of two environmental factors, ambient ozone $\left(0_{3}\right)$ and ambient temperature, upon the daily work performances of these individuals. ${ }^{2}$ Since each individual is separately analyzed, the host of plausible confounding influences (e.g., experience, biological endowments, health his-

\footnotetext{
Received for publication November 5, 1979. Revision ac cepted for publication October 21, 1980.

* University of Wyoming and Mathtech, Inc.

This research, originally suggested by Donald Gillette, was supported by the U.S. Environmental Protection Agency.

${ }^{1}$ See Freeman (1979, chap. 7) for a discussion.

2 In a laboratory experiment, Raven et al. (1976) found that lung function of nineteen adult males had declined by $4 \%$ to $7 \%$ following four hours of physical exertion in an environment resembling frequent ambient air conditions in southern California. No interactions between ambient temperature, ambient pollutants, or smoking habits were evident. Younger subjects appeared to be more sensitive to pollution and temperature than did older subjects. Qualitatively similar findings are presented in Kagawa and Toyama (1975).
}

tories, etc.) to which one must devote attention when dealing with the fictional "representative" individual are relevant here only insofar as they change within the short time periods being considered.

\section{The Picker's Supply of Effort}

The occupation of citrus harvesting has that ease of entry and exit, geographical and numerical scope, and absence of idiosyncratic (i.e., heterogeneous, highly-differentiated, task-specific skills enabling the current occupant to possess a degree of monopolistic advantage) characteristics that Doeringer and Piore (1971) term the secondary labor market. Harvesting operations in citrus groves are highly labor-intensive. Except for standardized ladders, cutting shears, and bags in which to deposit picked fruit, complementary capital inputs exercise no influence on the individual picker's output. Moreover, there are no good economic or even technical substitutes for the picker. His output, boxes of fruit picked, is readily defined, measured, and monitored, and is independent of the activities of other members of his picking crew. ${ }^{3}$ Picking procedures, which are standardized from one grove to another, do not require the picker to take involuntary leisure. In each grove, he is paid a predetermined piecework wage rate that varies directly with the difficulty of the picking opportunity, as determined by fruit type, size, and density, and tree height. A picker's earnings in a grove are the number of boxes of fruit he picks multiplied by the per box wage rate. Since all fruit meeting prespecified conditions for ripeness and size is to be picked, pickers have little, if any, incentive on a particular day to urge each other to slow the rate of pick, given that all pickers are at least earning the minimum wage. To do so would reduce the earnings of the better pickers without enhancing the earnings or reducing required work effort of the slower pickers.

\footnotetext{
${ }^{3}$ See Crocker and Horst (1977, pp. 9-12) for a description of the procedures used to assign pickers to rows.
} 
Since there are several thousand pickers employed in any one crop season, we view the picker as a wage-taker. ${ }^{4}$

The Lagrangian for the utility maximization problem the picker faces daily is

$$
\begin{aligned}
L= & U(I, H)+\lambda[I-w(G) \\
& \cdot B(E, G, H(E, G))-\bar{M}],
\end{aligned}
$$

where $U(\cdot)$ is concave and all partial derivatives are twice continuously differentiable. We assume that $U_{I}>0, U_{H}<0, U_{I I}<0, U_{H H}<0$, and $U_{I H} \leq$ 0 . This formulation states that the picker's level of utility varies positively each day with his consumption expenditures and savings, $I$, for that day, and negatively with the number of hours, $H$, he harvests fruit that same day. His daily consumption expenditures and savings are equal to his daily earnings from harvesting fruit plus whatever nonharvesting income, $\bar{M}$, he obtains. Nonharvesting income is fixed for the day in question. The amount of fruit, $B$, the picker harvests depends on the hours he practices harvesting, with both the amount and the hours depending on environmental, $E$, and grove, $G$, conditions. The wage, $w$, for each box of fruit he harvests varies only with grove conditions. Finally, income taxes and minimum wages are assumed to have no effect upon his work effort. ${ }^{5}$

The necessary conditions for an interior utility maximum of (1) are

$$
\begin{aligned}
& U_{I}+\lambda=0, \\
& U_{H}-\lambda w B_{H}=0,
\end{aligned}
$$

and the constraint.

Expressions (2) and (3) are, respectively, the marginal utility of earnings and the marginal disutility of work-hours, presuming that the opportunity to acquire earnings by harvesting fruit exists. Taken together (2) and (3) imply

$$
\frac{U_{H}}{U_{I}}=-w B_{H},
$$

which is the value of work to the picker and the rate at which he is willing to substitute leisure for earnings. Simultaneous individual fruit grower

\footnotetext{
${ }^{4}$ Rosedale and Mamer (1974, p. 19) state that in 1973, 3,335 pickers were employed by the Coastal Growers Association of Ventura County alone.

5 All pickers studied regularly earned more than the minimum wage, although, since they were in the lowest tax bracket, marginal income tax rates seem unlikely to have exercised a major influence upon work effort.
}

and individual picker utility maximization requires that

$$
C_{B}=-w B_{H}
$$

where $C_{B}$ is the rate at which the grower's expected income changes in response to changes in boxes of fruit harvested. ${ }^{6}$

From the picker's perspective, $w$ is predetermined. Temporarily assume that all groves are identical, except that they differ in size and therefore require differing numbers of hours for the picker's crew to harvest. This implies that the piecework rate will be constant across groves and that the picker's earnings opportunities in fruit harvesting will differ only according to the numbers of hours it will take his crew to harvest each grove.

At the beginning of any given day, the picker faces the situation depicted in figure 1. Each

Figure 1.-Hours-Earnings OPPortunities

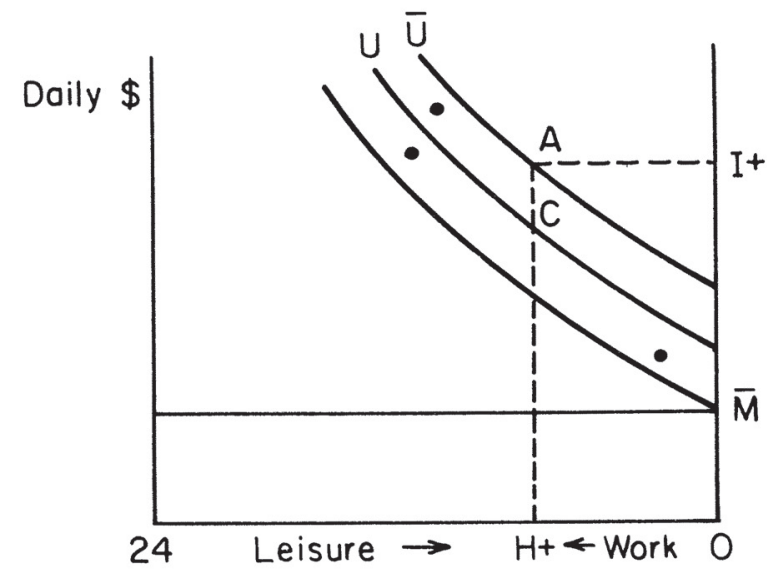

point in the figure represents an hours-earnings opportunity, one point to an opportunity. The opportunities need not involve citrus picking. Presume that $\bar{U}$, which passes through point $\mathrm{A}$, is the highest indifference curve passing through any of these points. Point $\mathrm{A}$, where the picker expects to earn $\mathrm{I}^{+}$dollars for $\mathrm{H}^{+}$hours of work, is therefore the earnings opportunity the picker will select for the day in question. On some days the opportunity set may not have any points lying on an indifference curve above that intersecting $\bar{M}$, the daily income the picker receives when he does not work. Given that the picker's hours-

\footnotetext{
${ }^{6}$ See Crocker and Horst (1977, pp. 27-31) for a development of the grower's harvest decision problem.
} 
earnings opportunities differ from day to day, the level of utility he expects to attain will also differ daily.

The above reasoning is not altered by the fact that grove attributes are dissimilar across groves. Growers attempt to adjust per box wage rates so that for any particular expenditure of his hours over the picking day, the picker expects his earnings, for given environmental conditions, to be (nearly) equal from one grove to another.

Once the picker is in a grove, he may discover that his initial perception of the hours-earnings opportunity was mistaken. For example, he may find that his earnings are distressingly low because unexpectedly severe environmental conditions are reducing his picking prowess. Similarly, he may find that the per box wage rate being paid is imperfectly adjusted to grove attributes so that his earnings for a given time expenditure are different than he had been led to expect. As a result, the level of utility he achieves may only be $U$, rather than $\bar{U}$. If the cause of this is air pollution and if the picker has disregarded air pollution in his original assessment of the earnings opportunity, the additional earnings while working $\mathrm{H}^{+}$hours he must receive in order to remain on $\bar{U}$, his expected level of utility, are $A C$. $A C$ thus represents a measure of the Hicksian compensating surplus. It is the economic loss caused by poor environmental conditions that attaches to the picker. In our empirical results, we obtain a measure of $A C$ for air pollution and temperature differences. Assuming that crew work-hours on the day in question do not change, $A C$ overstates the required compensation since the picker is constrained to work the same hours as the crew.

\section{The Data}

Data on the daily work performances and working conditions in 1973 and/or 1974 for more than 200 individual pickers were collected from citrus packing houses and labor camps in southern California. ${ }^{7}$ Daily or hour-by-hour air pollu-

\footnotetext{
7 Worker performance data were obtained from the San Gabriel Valley Labor Association of Cucumonga, the Lemoneira Ranch of Santa Paula, the River Growers Association of East Highlands, and Irvine Valencia Growers of Irvine. Grove condition data were provided by Upland Lemon Growers of Upland, Lemoneira Ranch of Santa Paula, Western Fruit Growers Packing Company of Mentone, Irvine Valencia Growers of Irvine, and Corona College Heights Citrus Company of Riverside.
}

tion and temperature data were obtained for the single monitoring sites closest to picking locations from records maintained by the Statewide Air Pollution Research Center at the University of California, Riverside. Several possible sources of measurement error are present in the environmental conditions data as well as the work performance data. These errors seem most important in the environmental conditions data, particularly the air pollution data. For example, it is not known whether the levels of air pollution recorded at the monitoring sites have a positive or negative bias, or even if they are biased at all. Furthermore, most of the monitoring stations used to determine air pollution and temperature levels for the grove locations are five to eight miles away. The stations are typically in downtown areas and at somewhat lower elevations than the groves.

In the work performance data, only the daily number of hours worked by a picker seems a possible nontrivial source of error. This number of hours is rounded off to the nearest half-hour in the picking records. In circumstances where the work-day has been rather short, this could lead to some bias in estimates, although it seems likely there is no systematic bias with respect to the sign of the error.

\section{Estimation}

In order to estimate the model of section II, it is convenient to use the picker's inverse supply function, the function in which earnings are determined by hours worked and exogenous factors, such as air pollution, that can be responsible for discrepancies between expected and realized earnings. ${ }^{8}$ After some experimentation with the picking histories of four experienced pickers who worked more-or-less continuously harvesting lemons over an entire year, a number of empirically inspired restrictions were placed upon the separate earnings expressions finally estimated for seventeen other pickers. The basic specification selected for estimation was multiplicative. This daily earnings expression can be estimated by ordinary-least-squares since values

\footnotetext{
${ }^{8}$ This supply function is simply the mirror image of the hours-earnings indifference locus in figure 1 . Since the indifference locus has a negative slope throughout, the slope of the supply function is the negative of the picker's marginal rate of substitution between earnings and leisure.
} 
of the dependent variable are fairly evenly distributed over a wide interval for each picker and since all the independent variables, including work hours, are exogenously determined.

Table 1 gives the variable descriptions, while table 2 gives ordinary-least-squares estimates of the earnings expressions for 17 pickers. The 4 preliminary test pickers are not included. ${ }^{9}$

Of the seventeen pickers for whom earnings expressions are presented in table 2 , nine $(1,3,5$, $7,9,10,15,16,17)$ have statistically significant air pollution coefficients at the 0.10 level or better of the one-tailed $t$-test. Six $(3,5,6,8,10,12)$ of the temperature coefficients are significant, but only three $(3,5,10)$ pickers have both coefficients significant. With but one exception (daily ozone for 12), air pollution and temperature have the negative signs consistent with the maintained hypotheses that higher levels of each have detrimental effects upon picker earnings. ${ }^{10}$ The standard errors of both coefficients are probably somewhat inflated since the simple correlation coefficients between the two are typically between 0.5 and 0.8 , with the bulk being around 0.6. Since air pollution appears to be somewhat more statistically robust, subsequent discussion concentrates upon it.

\footnotetext{
${ }^{9}$ In addition to the independent variables of table 2, several other variables were investigated for the four test pickers. The introduction of most of these other variables was motivated by conversations with labor camp managers rather than from properties of our model of the picker's decision problem. For example, managers widely believe that, because of planned and realized picker weekend activities, picker performance decreases markedly on Fridays and Mondays. For the four test workers, however, the estimated coefficients for Friday and Monday dummy variables were not significantly different from zero. A second common managers' observation is that many pickers set an earnings goal and will not work as productively once this goal is achieved. The validity of this hypothesis was checked by including a measure of the picker's total earnings in previous weeks. Again, statistically significant coefficients were not obtained. Finally, the managers believe that having multiple groves worked in a day seriously impairs the picker's productivity. It is thought that each move to a different grove causes the picker to go through another "warm-up" period, thus slowing down his picking output. Inclusion of a variable representing the daily number of groves picked did not result in a significant coefficient for any test picker.

Measures of the daily variances and maximum hourly ozone faced by the four test pickers were also calculated. They were highly collinear with the arithmetic mean measures and, when included in the four pickers' earnings expressions, were not significant.

${ }^{10}$ It is practically unheard of for daytime temperatures in the citrus growing areas of southern California to approach freezing. In the summertime, daytime temperatures exceeding one hundred degrees are common.
}

Table 1.-Variable Descriptions

Daily Earnings $=$ the picker's daily gross earnings from picking activities for each grove worked.

Boxes per tree $=$ the mean number of field boxes picked per tree during the work-day by the picker's crew in a specific grove. The fewer the boxes per tree, the greater the difficulty of the picking opportunity and, therefore, the fewer the boxes the individual will be able to harvest. However, the wage rate per box picked is adjusted with crew boxes per tree, fruit size, and tree height according to a standard formula in order to keep the representative picker's earnings similar across groves. The regression coefficients attached to this and the other two grove attribute variables therefore represent the deviation in the individual picker's adjustment to the change in the variables from the adjustment of the representative picker. If the picker were the representative picker, the variables would have zero coefficients since his earnings (the product of boxes he picks and the pay per box) would be identical across groves.

Fruit size $=$ the number of fruit required to fill a field box. Since picking is reputed to be easier with larger fruit, the pay per box declines with increases in the variable.

Tree height $=$ an index which monotonically increases with tree height. The respective tree heights assigned, one to a grove, are 4.5 feet, 7.0 feet, 10.5 feet, and 15.0 feet.

Hours worked $=$ the number of hours worked by the crew and the picker during the day. All days in which the picker worked fewer hours harvesting fruit than did the crew were excised from the sample. No days in which the crew worked less than 2 hours were included in any picker's sample.

Daily ozone $=$ the arithmetic mean 24-hour ambient concentration on the work day of $0_{3}$ in parts per million by volume as measured by the CHEMILUM method.

Hourly ozone $=$ the arithmetic mean of the hourly ambient concentration of $0_{3}$ occurring during the time interval the picker was engaged in citrus harvesting.

Temperature $=$ the maximum hourly arithmetic mean ambient dry-bulb temperature in $\mathrm{F}^{\circ}$ on the work-day.

A substantial literature now exists demonstrating declining marginal productivity of increased hours within the work-day. ${ }^{11}$ The cases studied in this paper are not representative of most jobs. Nevertheless, the individuals in table 2 do engage in strenuous physical activity over work-days that can vary from 2 to 12 hours. In spite of the strenuousness of their activity, the marginal value product of hours for nearly all the pickers in table 2 is very close to being a constant.

In spite of the near-unitary elasticity of earnings with respect to hours in table 2 , it is possible that poor environmental conditions and hours interact to result in a declining marginal value product. The hypothesis is that picker responsiveness to air pollution increases with the length of the work-day. Rather than arbitrarily specifying the form of the interaction between hours and

11 See Feldstein (1967), Barzel (1973), and Rosen (1976), for example. 


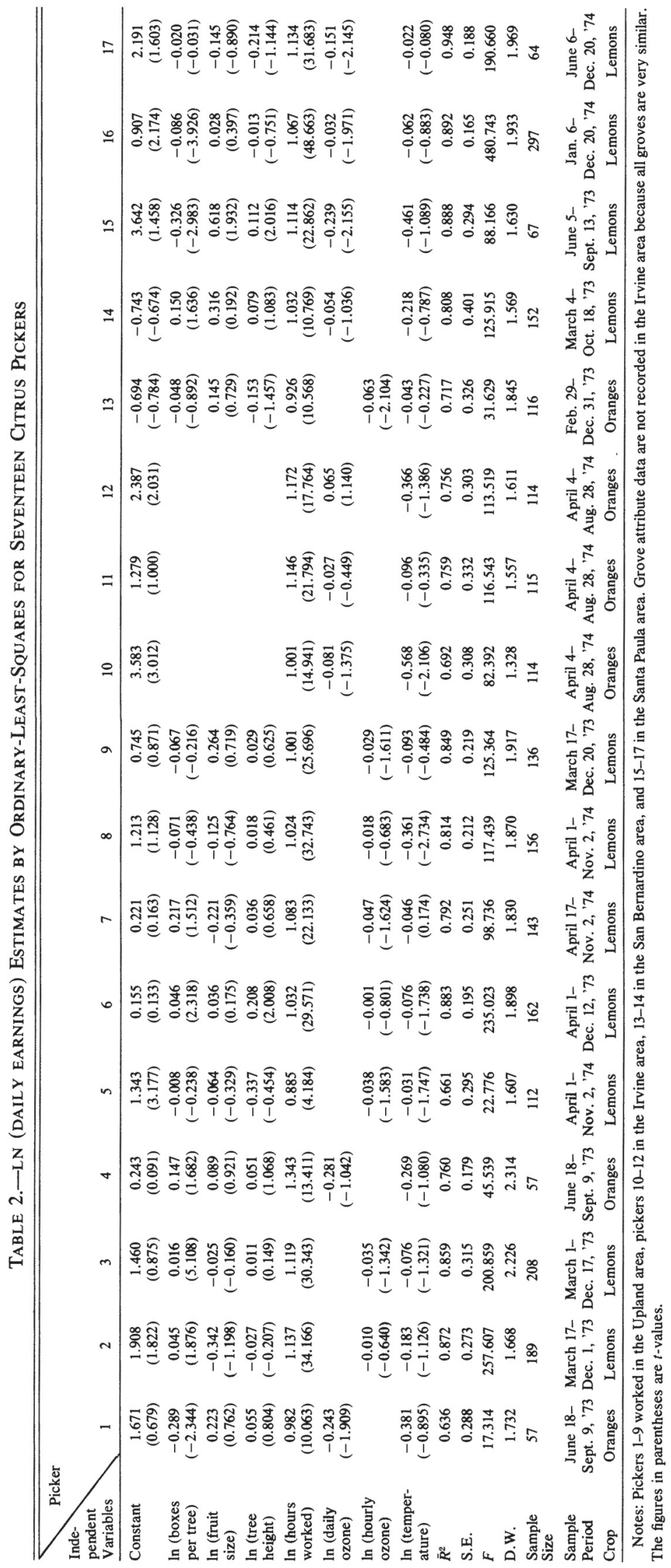


air pollution by adding a combined variable to the expressions of table 2, we have partitioned the work-day for each picker by the number of hours he worked. The specifications are identical to those of table 2. To test for statistically significant differences in the air pollution coefficients across partitions, the covariance $F$-test for single coefficients developed by Tiao and Goldberger (1962) was used. The results of the test are presented in table 3.

At best, the evidence in table 3 for longer hours worsening the negative effects of air pollution upon picker productivity is mixed. Fourteen of the pickers now have a significant air pollution coefficient, including five $(6,11,12,13,14)$ for whom the table 2 coefficient was not significant. Twelve of the seventeen pickers have coefficients of greater negative magnitude for days in which they worked 7 hours or more. However, of the twelve, four $(2,4,5,8)$ do not have a significant difference between the coefficients. Finally, four pickers $(10,11,12,13)$ have negative and significant coefficients only for days when they worked less than 7 hours. These coefficients are significantly different from those applying to work-days of 7 or more hours.

\section{Measures of Required Compensation}

Here we use the results of table 3 to calculate the compensation the picker requires to make him indifferent between the presence or absence of ozone air pollution. Assuming that the elasticity of the picker's earnings with respect to air pollution is a constant, his required income compensation, $\bar{V}$, per grove he picked during the period of observation is

$$
\bar{V}=\frac{\hat{b}}{n} \sum_{i=1}^{n} \frac{I_{i}}{i^{\text {th }} \text { ozone observation }},
$$

where $\hat{b}$ is the elasticity of earnings with respect to air pollution, $n$ is the number of earnings observations, $I$ is earnings in a grove, and $i$ indexes the groves in which the picker harvested fruit.

Only those partitionings of table 3 yielding significant and negative air pollution coefficients are employed to perform the calculations embodied in table 4. However, $n \bar{V}$ and $\left(n \bar{V} /\left(\Sigma I_{i}+n \bar{V}\right)\right) 100$, which respectively represent the total required compensation, and this required compensation as a percentage of what the picker's harvest earnings would have been in the absence of air pollu-

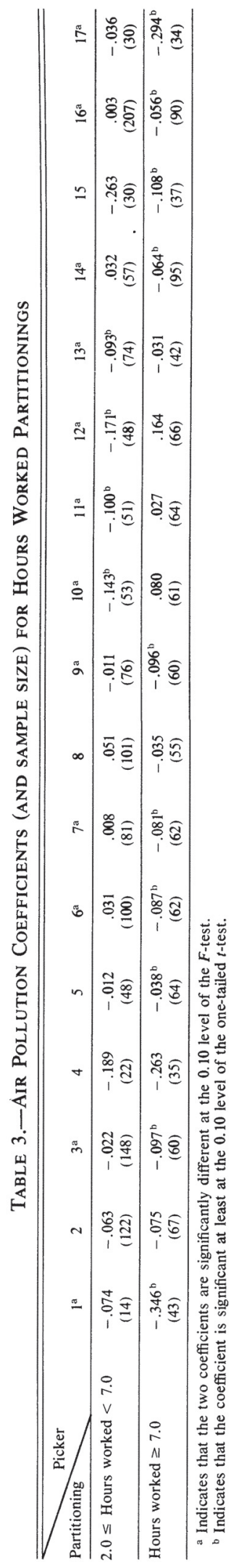


Table 4.-Required Picker Compensation

\begin{tabular}{|c|c|c|c|c|c|c|}
\hline \multirow[b]{2}{*}{ Picker } & \multirow[b]{2}{*}{$\hat{b}$} & \multirow[b]{2}{*}{$\Sigma I_{i}$} & \multirow[b]{2}{*}{$\bar{V}$} & \multirow[b]{2}{*}{$n \bar{V}$} & \multirow{2}{*}{$\frac{n \bar{V}}{\Sigma I_{i}+n \bar{V}}$} & \multirow{2}{*}{100} \\
\hline & & & & & & \\
\hline 1 & -.346 & $\$ 1,213.50$ & $\$ 1.695$ & $\$ 96.62$ & $7.4 \%$ & \\
\hline $2^{\mathrm{a}}$ & - & - & - & - & - & \\
\hline 3 & -.097 & $3,586.13$ & 0.496 & 103.17 & 2.9 & \\
\hline $4^{a}$ & - & - & - & - & - & \\
\hline 5 & -.038 & $1,334.59$ & 0.127 & 14.22 & 1.1 & \\
\hline 6 & -.087 & $3,163.33$ & 0.685 & 110.97 & 3.4 & \\
\hline 7 & -.081 & $2,619.37$ & 0.197 & 28.17 & 1.1 & \\
\hline $8^{a}$ & - & - & - & - & - & \\
\hline 9 & -.096 & $1,821.46$ & 0.121 & 16.46 & 0.9 & \\
\hline 10 & -.143 & $2,063.40$ & 0.685 & 78.09 & 3.6 & \\
\hline 11 & -.100 & $2,313.10$ & 0.418 & 48.07 & 2.0 & \\
\hline 12 & -.171 & $2,650.36$ & 0.877 & 99.98 & 3.6 & \\
\hline 13 & -.093 & $1,239.08$ & 0.080 & 9.28 & 0.7 & \\
\hline 14 & -.064 & $3,529.50$ & 0.173 & 26.30 & 0.7 & \\
\hline 15 & -.108 & $1,033.85$ & 0.527 & 35.31 & 3.3 & \\
\hline 16 & -.056 & $4,861.93$ & 0.408 & 121.18 & 2.4 & \\
\hline 17 & -.294 & $1,174.40$ & 0.742 & 47.49 & 3.9 & \\
\hline
\end{tabular}

tion, use earnings over all work-day lengths for the entire period of observation as the basis for the calculations. The calculations reveal that required picker compensation ranges from $0 \%$ to $7.4 \%$ of what earnings would have been in the absence of air pollution. The arithmetic mean required compensation for the seventeen pickers is $2.2 \%$, with the median being $2.0 \%$. The weighted mean is $2.1 \%$, where the weights are the number of daily earnings observations on each picker. Assuming that the representative picker could earn approximately $\$ 5,000$ in 1974 by working full-time, this implies that prevailing levels of air pollution in southern California in 1974 might have cost him as much as the utility equivalent of $\$ 100-110$. This is probably an upper bound on his losses since we have limited our inquiry to circumstances where the picker never chose to substitute leisure for earnings.

\section{Summary and Conclusions}

The extent to which citrus harvesting has little or much in common with other occupations is arguable. At a minimum, it nevertheless has those attributes of strenuous physical activity and repetition found in a fairly wide variety of other semi-skilled jobs. It is in these jobs where one might reasonably expect to find declining marginal value productivity as fatigue and ennui set in with extensions of the work-day. For the limited but well-defined case studied here, we found no evidence that the marginal value product, as registered in daily earnings, declines as more hours are worked each day. We did find, however, that the ozone air pollution prevalent in southern California does reduce daily earnings, perhaps by as much as $2.0 \%$ on the average. However, there exist order-of-magnitude differences in the losses among pickers. These results have been obtained on the presumption that air pollution and other environmental conditions influence only the picker's ability to harvest fruit. No account has been taken of the possibility that he may simply dislike the presence of a poor environment and thereby be induced to reduce his work effort.

Similarly detailed data sets might allow more ambitious applications to other occupations of the basic model used here to estimate the compensating surpluses or variations that workers require for changes in workplace conditions. Though we have not attempted to explain the wide differences in compensating surpluses for air pollution exposures that we obtained as between and among the workers in our sample, the fact of these differences suggests that studies which employ worker and/or time aggregates might err: it could be that estimates derived from aggregated data represent the behavior of neither sensitive nor insensitive individuals but rather a weighted sum of the two for which it is impossible to disentangle the distinct contribution of each type of individual. For many policy questions involving workplace and environmental conditions, it is the sensitive individual, rather than the "representative" individual, who must be identified. 


\section{REFERENCES}

Barzel, Yoram, "The Determination of Daily Hours and Wages," Quarterly Journal of Economics 87 (May 1973), 220-238.

Crocker, Thomas, and Robert Horst, Jr., Oxidant Air Pollution and Work Performance of Citrus Harvest Labor (Research Triangle Park, N.C.: USEPA-600/5-77-013, Sept. 1977).

Doeringer, Peter, and Michael Piore, Internal Labor Markets and Manpower Analysis (Lexington, Mass.: D.C. Heath and Co., 1971).

Feldstein, Martin, "Specification of the Labour Input in the Aggregate Production Function," The Review of Economic Studies 34 (Oct. 1967), 375-386.

Freeman, A. Myrick III, The Benefits of Environmental Improvement (Baltimore: Johns Hopkins University Press, 1979).

Kagawa, Jun, and Toshio Toyama, "Photochemical Air Pollution," Archives of Environmental Health 30 (Mar. 1975), 117-123.

Raven, Peter B., J. A. Gliner and J. C. Sutton, "Dynamic Lung Function Changes Following Long-Term Work in a Polluted Environment," Environmental Research 12 (Aug. 1976), 18-25.

Rosedale, D., and J. Mamer, Labor Management for Seasonal Farm Workers: A Case Study, Berkeley, California Agricultural Experiment Station, Information Series in Agricultural Economics, No. 74-1 (1974).

Rosen, Harvey, "Taxes in a Labor Supply Model with Joint Wage-Hours Determination," Econometrica 44 (May 1976), 485-507.

Smith, Robert S., "The Feasibility of an 'Injury Tax' Approach to Occupational Sáfety,' Law and Contemporary Problems 38 (Summer-Autumn 1974), 730-744.

Thaler, Richard, and Sherwin Rosen, "The Value of Saving a Life: Evidence from the Labor Market," in N. Terleckyj (ed.), Household Production and Consumption (New York: Columbia University Press, 1976).

Tiao, George, and Arthur Goldberger, Testing Equality of Individual Regression Coefficients, University of Wisconsin-Madison, Social Systems Research Institute, Workshop on the Economic Behavior of Households, Paper 6201 (1962).

Viscusi, W. Kip, "Job Hazards and Worker Quit Rates: An Analysis of Adaptive Worker Behavior," International Economic Review 20 (Feb. 1979), 29-58. 